\title{
Cardiovascular features of possible autonomous cortisol secretion in patients with adrenal incidentalomas
}

\author{
Emilia Sbardella1,*, Marianna Minnetti1,*, Denise D'Aluisio², Laura Rizza1, Maria Rosaria Di Giorgio', \\ Fabio Vinci ${ }^{2}$, Riccardo Pofi ${ }^{1}$, Elisa Giannetta ${ }^{1}$, Mary Anna Venneri ${ }^{1}$, Annarita Vestri ${ }^{3}$, Sergio Morelli², \\ Andrea Lenzi ${ }^{1}$ and Andrea M Isidori ${ }^{1}$
}

${ }^{1}$ Departments of Experimental Medicine, ${ }^{2}$ Internal Medicine, and ${ }^{3}$ Public Health and Infectious Diseases, Sapienza University of Rome, Rome, Italy
Correspondence should be addressed to A M Isidori

Email

andrea.isidori@uniroma1.it

\begin{abstract}
Background: Low-grade incomplete post-dexamethasone cortisol suppression in patients with adrenal incidentalomas - recently defined as possible autonomous cortisol secretion (pACS) - has been associated with increased cardiovascular events and mortality. However, prospective studies documenting cardiac abnormalities in these patients are lacking.

Subjects and methods: Between July 2016 and September 2017, 71 consecutive patients with adrenal lesions were prospectively screened for hypercortisolism by dexamethasone suppression test (NCT 02611258). Complete anthropometric, metabolic and hormonal parameters were recorded along with full cardiac ultrasound assessment and noninvasive measurement of arterial stiffness. All patients underwent chemical-shift magnetic resonance imaging to characterize the lesions. Cardiovascular outcomes were recorded in blind.

Results: According to post-dexamethasone suppression cortisol values (post-DST), 34 patients had pACS and 37 nonfunctioning adenomas (NFA). The two groups were similar in sex, BMI, age distribution, cardiovascular risk factors and comorbidities. Left ventricular mass index (LVMIBSA) was increased in pACS compared to NFA $(P=0.006)$ and mildly correlated to the post-DST cortisol level (rho=0.347; $P=0.004$ ). The post-DST cortisol levels explained up to $13.7 \%$ of LVMI $^{\mathrm{BSA}}$ variance $(P=0.002)$. Compared to NFA, patients with pACS had a higher prevalence of diastolic dysfunction (35.1\% vs $82.6 \% ; P=0.001)$ and worse arterial stiffness assessed by pulse wave velocity $(P=0.033)$.

Conclusions: In apparently asymptomatic patients, mild autonomous cortisol secretion can sustain early cardiac and vascular remodeling, independently of other risk factors. The morphological and functional cardiovascular changes observed in pACS underline the need for further studies to correctly define the long-term management of this relatively common condition.
\end{abstract}

\section{Introduction}

Adrenal incidentalomas are clinically silent masses discovered inadvertently during diagnostic imaging procedures performed for unrelated reasons. Depending on the criteria applied, up to $50 \%$ of patients with

www.eje-online.org

https://doi.org/10.1530/EJE-17-0986
(C) 2018 The authors Published by Bioscientifica Ltd. Printed in Great Britain
European Journal of Endocrinology (2018) 178, 501-511 
a partial, incomplete suppression of the hypothalamicpituitary-adrenal (HPA) axis without the typical signs of overt cortisol hypersecretion (i.e. moon face, truncal obesity, easy bruising, thin extremities, proximal myopathy, cutaneous purple striae) (2). It is widely recognized that overt endogenous hypercortisolism (Cushing's syndrome CS) is associated with excessive mortality, mainly due to cardiovascular (CV) disease (3). However, the mechanism leading to cardiac damaging remains unclear $(3,4)$. For this reason, the ERGO trial (Endocrine Cardiomyopathy in Cushing Syndrome: Response to Cyclic GMP PDE5 inhibitOrs) was designed. Retrospective analysis unexpectedly revealed that also asymptomatic patients with adrenal adenomas and low-grade autonomous cortisol secretion suffer from a higher rate of $\mathrm{CV}$ events and mortality than patients with normal HPA axis suppression $(5,6,7)$. Despite these epidemiological associations, only two small studies investigated morphological and functional changes to the CV system in patients with mild hypercortisolism $(8,9)$. In particular, they did not investigate whether $\mathrm{CV}$ changes correlated to cortisol levels. The fact that pACS is, by definition, asymptomatic prompted us to investigate the cardiac features of these patients, taking advantage of patients screened during enrollment for the ERGO trial. All patients with pACS underwent a complete ultrasound assessment of structural and functional left ventricular (LV) abnormalities accompanied, for the first time, by arterial stiffness assessment. Patients were then stratified according to response to the dexamethasone suppression test. The main hypothesis of this sub-analysis of the ERGO trial was to test whether left ventricular mass index (LVMI) is higher in pACS than in nonfunctioning adenoma (NFA) patients.

\section{Subjects and methods}

\section{Protocol}

109 consecutive outpatients aged between 18 and 75 years with an incidentally detected adrenal mass were screened for inclusion in the ERGO trial (NCT02611258). The main inclusion criterion to enter the ERGO trial is a diagnosis of CS. The study population of the current sub-analysis consists of all screened patients with an adrenal lesion not matching a diagnosis of CS (Fig. 1). All patients were evaluated at the Department of Experimental Medicine, Sapienza, University of Rome between July 2016 and September 2017.
All patients were clinically examined and evaluated for signs and symptoms typical of adrenal hormones excess. Anthropometric measurements were assessed by the same person. BMI was calculated by dividing weight (in $\mathrm{kg}$ ) by height (in $\mathrm{m}^{2}$ ). Arterial hypertension was defined as systolic blood pressure (SBP) $\geq 140 \mathrm{mmHg}$ and/or diastolic blood pressure (DBP) $\geq 90 \mathrm{mmHg}$ on repeated evaluations and/or reported use of antihypertensive medication (10). Type 2 diabetes mellitus (T2DM) was diagnosed according to ESC guidelines or reported use of antidiabetic drugs (11). Dyslipidemia was diagnosed according to ESC/ EAS Guidelines or reported use of hypolipidemic drugs (12). Current smokers were patients who smoked any tobacco during the observation period or patients who had smoked in the last twenty years. The study was performed following Declaration of Helsinki principles and the protocol approved by the Ethics Committee of 'Sapienza' University of Rome on the 19 November 2015 with reference number 3875 , and subsequently registered on NIH (NCT02611258). An informed consent has been obtained from each patient.

\section{Biochemical and radiological evaluation}

Fasting baseline sampling was performed for measurement of blood glucose, insulin, glycated hemoglobin, sodium, potassium, creatinine, total cholesterol, HDL cholesterol and triglycerides. Insulin resistance was assessed using HOMA-IR.

The functional status of incidentally discovered adrenal masses was determined according to the ESE 2016 guidelines (2). Blood tests included an endocrine workup taken after an overnight fast and performed between 08:00 h and 09:00h. Baseline cortisol (radioimmunoassay), ACTH (immunoradiometric assay), dehydroepiandrosterone sulfate (DHEAS) (chemiluminescence), androstenedione (radioimmunoassay), 17OH-progesterone (radioimmunoassay) and aldosterone/renin ratio (radioimmunoassay) were measured in all patients. Urinary free cortisol (UFC) (radioimmunoassay) and 24-h urine metanephrine (radioimmunoassay) tests were also performed.

Adrenal lesions were discovered by abdominal ultrasonography, CT scan or MRI and confirmed in all cases with chemical shift MRI. All adrenal masses were larger than $10 \mathrm{~mm}$ and showed a MRI pattern consistent with benign adenoma (i.e. regular margins, loss of signal intensity on out-of phase images compared with in-phase images, size $<6 \mathrm{~cm}$ ).

Of the 109 patients with adrenal incidentalomas, those with overt Cushing's syndrome, pheocromocytoma, 


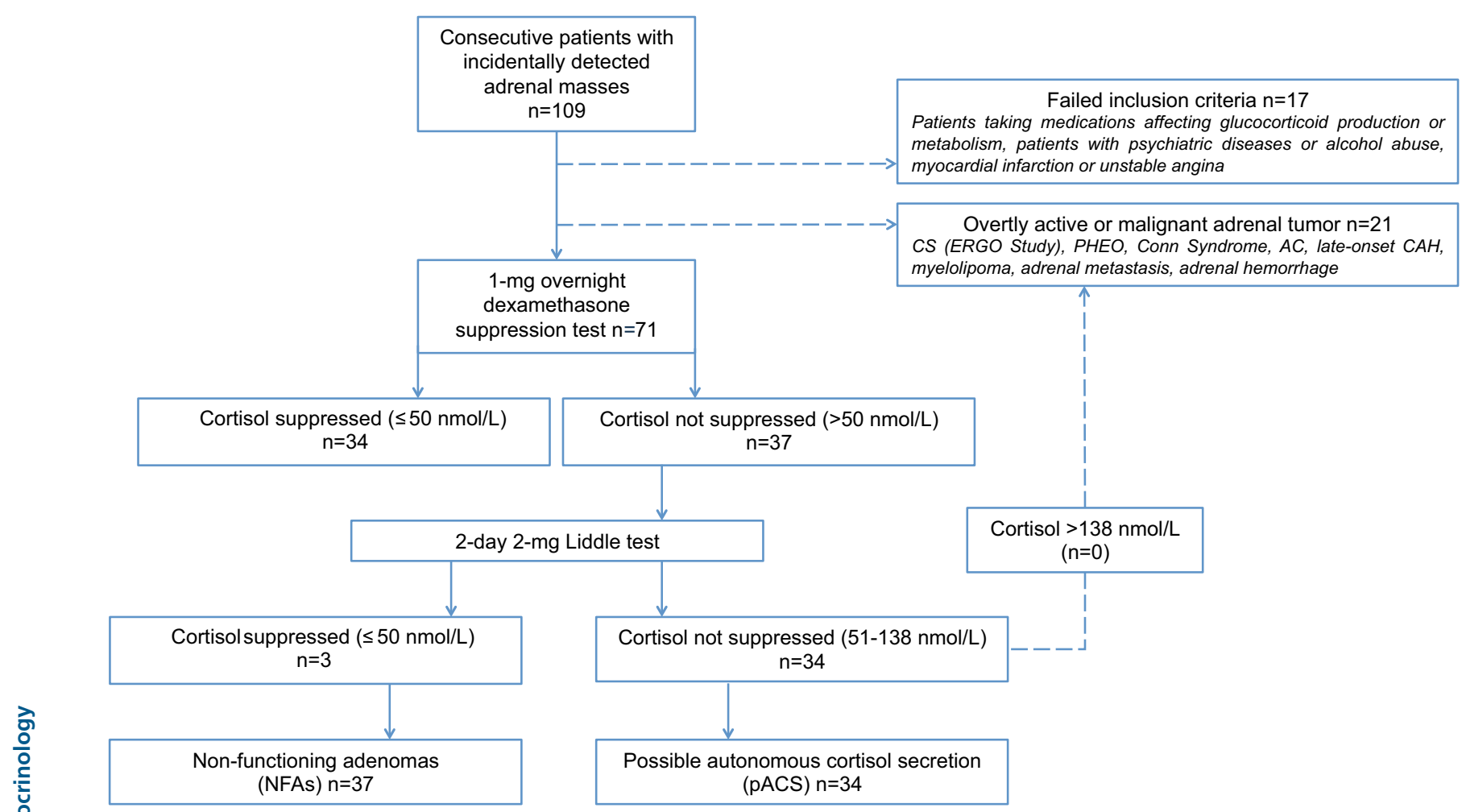

\section{Figure 1}

Study flow diagram. AC, adrenal carcinoma; $\mathrm{CAH}$, congenital adrenal hyperplasia; CS, Cushing syndrome; NFA, non-functioning adenoma; PHEO, pheochromocytoma; pACS, possible autonomous cortisol secretion.

Conn syndrome, adrenocortical carcinoma, late-onset congenital adrenal hyperplasia, myelolipoma, adrenal metastasis and adrenal hemorrhage were not included in the current analysis. Patients taking medications influencing glucocorticoid production or metabolism, patients with psychiatric diseases or alcohol abuse, myocardial infarction or unstable angina, history of malignancy, infections and infiltrative diseases potentially affecting the adrenal glands were also excluded. This left a group of 71 patients (Fig. 1).

Interpretation of the results of the $1 \mathrm{mg}$ overnight dexamethasone test ( $1 \mathrm{mg}$-DST) was based on the 2016 European Society of Endocrinology guidelines (2). $1 \mathrm{mg}$-DST cortisol levels between 51 and $138 \mathrm{nmol} / \mathrm{L}$ were considered as possible autonomous cortisol secretion (pACS) and greater than $138 \mathrm{nmol} / \mathrm{L}$ were considered as Cushing's syndrome sustained by autonomous cortisol secretion. $1 \mathrm{mg}$-DST cortisol levels below $50 \mathrm{nmol} / \mathrm{L}$ were considered to identify patients with nonfunctioning adenoma (NFA). Since the $1 \mathrm{mg}$-DST has the same sensitivity (98\%) but lower specificity than the classic 2-day 2-mg Liddle test (2 mg-DST) (87.5 vs 97-100\%) (13), in all patients with $1 \mathrm{mg}$-DST cortisol above $50 \mathrm{nmol} / \mathrm{L}$, the test was confirmed by $2 \mathrm{mg}$-DST. In the final data set analysis, the cortisol values for patients with normal suppression on $1 \mathrm{mg}$-DST and the $2 \mathrm{mg}$-DST values for all remaining patients were combined (post-DST).

\section{Cardiovascular evaluation}

Transthoracic echocardiography was performed by a blinded outcome assessor using an Aplio CV Toshiba with a $3 \mathrm{MHz}$ transducer in 2D, Doppler, color-Doppler and Tissue Doppler Imaging (TDI). Patients were examined in the left lateral decubitus position according to the American Society of Echocardiography guidelines (14). Left ventricle end-diastolic diameter (LVED), interventricular septal thickness (IVS) and posterior wall thickness (PWT) were measured at end diastole. Left ventricular mass (LVM) was calculated by the corrected American Society of Echocardiography method: $\mathrm{LVM}=0.8$ $\left(1.04\left((\text { LVED + IVS + PWT })^{3}-(\text { LVED })^{3}\right)+0.6\right) . \quad$ LVM index (LVMI ${ }^{\mathrm{BSA}}$ ) was calculated as LVM divided by body surface area (BSA). LV hypertrophy was defined according to gender-specific criteria as $2 \mathrm{D}$ measurements greater than $88 \mathrm{~g} / \mathrm{m}^{2}$ in women and $102 \mathrm{~g} / \mathrm{m}^{2}$ in men. The relative wall 
thickness (RWT) was calculated as (IVS+PWT)/LVED. RWT $>0.42$ was considered pathologic. Patients with increased LVMI ${ }^{\mathrm{BSA}}$ and increased RWT were considered to have concentric LV hypertrophy, while those with increased $\mathrm{LVMI}^{\mathrm{BSA}}$ and normal RWT were considered to have eccentric LV hypertrophy. $\mathrm{LVMI}^{\mathrm{BSA}}$ is widely used in routine practice, and it has been documented to detect hypertension-related cardiac hypertrophy. We also calculated LVM normalized to height ${ }^{2.7}$ to obtain LVMI ${ }^{\text {h2.7 }}$, which is considered to be more sensitive in detecting obesity-related LVH (15).

Left atrial (LA) anteroposterior size was assessed in the parasternal long axis. Left ventricular ejection fraction (LVEF) was determined by manual tracing using Simpson's biplane method.

Left ventricular diastolic dysfunction (LVDD) was assessed by pulse-wave Doppler evaluating the following parameters: early-E-wave (E) and late A-wave (A) diastolic filling velocities and E/A ratio. TDI measurements were performed in the apical 4-chamber view and the sample volume was placed in the septal mitral annulus and lateral mitral annulus. Early diastolic tissue velocities $\left(E^{\prime}\right)$ from both the septal (E's) and lateral (E'l) wall were assessed and mean $\mathrm{E}^{\prime}\left(\mathrm{E}^{\prime} \mathrm{m}\right)$ was calculated; $\mathrm{E} / \mathrm{E}^{\prime}$ ratio was derived, reflecting the LV filling pressures. LVDD was diagnosed on the basis of E's $<8 \mathrm{~cm} / \mathrm{s}$ or $\mathrm{E}^{\prime} l<10 \mathrm{~cm} / \mathrm{s}$. Diastolic dysfunction (grade I, mild; grade II, moderate or grade III, severe) was quantified using EAE recommendations (16). Right ventricular function was assessed as the tricuspid annular plane systolic excursion (TAPSE). TAPSE $<17 \mathrm{~mm}$ is highly suggestive of $\mathrm{RV}$ (right ventricular) systolic dysfunction.

\section{Blood pressure and arterial stiffness}

Arterial stiffness and blood pressure (BP) were assessed by BPLab (Vasotens Technology), using brachial oscillometric blood pressure waves for a noninvasive estimation. The measurements were performed in the supine position after the patients had been resting for a minimum of $5 \mathrm{~min}$. The distance from the jugulum to the symphysis was measured in every patient. The optimal adult cuff was wrapped around the non-dominant arm. In a single session measurements of brachial systolic blood pressure (SBP) and diastolic blood pressure (DBP) were taken three times, at 5-min interval. Their average was used for analyses. During the BP measurement the pressure waveforms in the cuff were registered and digitalized. Thereafter, an aortic pulse wave was generated to derive the aortic pressure wave. The difference in time between the beginning of the first wave and the beginning of the second (reflected wave) was related to the distance from the jugulum to the symphysis, resulting in the pulse-wave velocity (PWV) in $\mathrm{m} / \mathrm{s}$. Therefore, PWV and reflected wave transit time (RWTT), which have been used to evaluate arterial stiffness, were obtained after the end of measurement.

\section{Statistical analysis}

Based on previously published data (17) describing $25 \mathrm{~g} / \mathrm{m}^{2}$ standard deviation (s.D.) for $\mathrm{LVMI}^{\mathrm{BSA}}$ in the population with hypercortisolism, and considering cautiously $20 \mathrm{~g} / \mathrm{m}^{2}$ as the minimal clinically relevant difference between groups, a calculated sample size of 54 would have provided $90 \%$ power to detect the specified minimum detectable difference in $\mathrm{LVMI}^{\mathrm{BSA}}$ at a 2-sided significance level of 0.05 .

Distribution of continuous variables was tested with the Shapiro-Wilk test; linearity was established by visual inspection of a scatterplot. Categorical variables were expressed as percentage and frequency; continuous variables were reported as mean and 95\% confidence interval $(95 \% \mathrm{CI})$ or median and interquartile range (25th-75th percentile). For group comparisons unpaired Student's $T$-test, Mann-Whitney, $\chi^{2}$ or Fisher's exact test were used as appropriate. A general linear model including the presence or absence of autonomous cortisol secretion as a fixed effect and factors known to affect cardiovascular features as covariates was developed. In the analysis of covariance (ANCOVA) model, log transformation or reciprocal transformation were used for skewed data. Regression analysis was performed to estimate the contributors to LVMI ${ }^{\mathrm{BSA}}$ variability. Standardized residuals were tested for normality. Homoscedasticity and homogeneity of variances were assessed by visual inspection. Multicollinearity was assessed by calculation of the variance inflation factor (VIF). Sensitivity analysis was performed excluding both patients with a diagnosis of diabetes mellitus and those with discrepancies between the two suppression tests. Correlations between parameters were analyzed using Pearson and Spearman's correlation coefficients. A $P<0.05$ was considered statistically significant. All statistical analyses were performed using SPSS software (Version 19.0; IBM, Normal).

\section{Results}

\section{Clinical and biochemical evaluation}

A total of 109 patients with incidentally discovered adrenal mass were screened in the ERGO trial, of whom 38 did 
Table 1 Clinical and biochemical characteristics of all enrolled subjects.

\begin{tabular}{l}
\hline \\
\hline Age (years)* \\
Male/Female gender \\
Body mass index $\left(\mathrm{kg} / \mathrm{m}^{2}\right)^{*}$ \\
Overweight patients \\
Obese patients \\
Diameter of adenoma $(\mathrm{mm})^{\S}$ \\
Blood glucose $(\mathrm{mg} / \mathrm{dL})^{*}$ \\
Glycated hemoglobin $(\%)^{*}$ \\
Insulin $\left(\mu \mathrm{U} / \mathrm{mL}^{*}\right.$ \\
HOMA-IR Index* \\
Total cholesterol $(\mathrm{mg} / \mathrm{dL})^{\S}$ \\
LDL cholesterol $(\mathrm{mg} / \mathrm{dL})^{\S}$ \\
HDL cholesterol $(\mathrm{mg} / \mathrm{dL})^{*}$ \\
Triglycerides $(\mathrm{mg} / \mathrm{dL})^{*}$ \\
Creatinine $(\mathrm{mg} / \mathrm{dL})^{*}$ \\
Sodium $(\mathrm{mmol} / \mathrm{L})^{\S}$ \\
Potassium $(\mathrm{mmol} / \mathrm{L})^{\S}$ \\
Hypertension \\
Number of antihypertensive drugs \\
$1-2$ \\
$3-4$ \\
Duration of hypertension* \\
$<10$ years \\
$10-20$ years \\
$>20$ years \\
Type 2 diabetes mellitus \\
Taking antidiabetic drugs \\
Dyslipidemia \\
Taking hypolipidemic drugs \\
Smoker ${ }^{+}$ \\
\hline
\end{tabular}

\begin{tabular}{c} 
Adrenal incidentalomas $(n=71)$ \\
\hline $67(59-72)$ \\
$24 / 47$ \\
$26.3(23.5-29.4)$ \\
$30 / 71(42.3 \%)$ \\
$17 / 71(23.9 \%)$ \\
$23.8(21.2-26.4)$ \\
$92(85-105)$ \\
$5.5(5.2-5.7)$ \\
$8.7(6.9-10)$ \\
$2(1.5-2.4)$ \\
$205(197-212)$ \\
$121(113-130)$ \\
$62(54-71)$ \\
$90(75-119)$ \\
$0.7(0.7-0.8)$ \\
$142(141-143)$ \\
$4.3(4.2-4.4)$ \\
$45 / 71(63.4 \%)$
\end{tabular}

\begin{tabular}{c}
\hline NFA $(n=37)$ \\
\hline $67(60-72)$ \\
$11 / 26$ \\
$25.9(23.7-31.2)$ \\
$15 / 37(40.5 \%)$ \\
$7 / 37(18.9 \%)$ \\
$20.2(17.2-23.1)$ \\
$90(85-96)$ \\
$5.5(5.3-5.7)$ \\
$8.6(6.6-10.4)$ \\
$1.9(1.4-2.4)$ \\
$199(187-210)$ \\
$114(102-126)$ \\
$59(53-67)$ \\
$104(83-131)$ \\
$0.7(0.7-0.8)$ \\
$142(141-143)$ \\
$4.2(4-4.3)$ \\
$23 / 37(62.2 \%)$
\end{tabular}

$30 / 45(66.7 \%)$

$15 / 45(33.3 \%)$

$17 / 23(73.9 \%)$

$6 / 23(26.1 \%)$

$21 / 45(46.7 \%)$

$16 / 45(35.5 \%)$

$8 / 45(17.8 \%)$

$9 / 71(12.7 \%)$

$8 / 9(88.9 \%)$

45/71 (63.4\%)

$14 / 45$ (31.1\%)

$24 / 71(33.8 \%)$

$10 / 23(43.5 \%)$

$10 / 23(43.5 \%)$

$3 / 23(13 \%)$

$2 / 37(5.4 \%)$

$1 / 2(50 \%)$

$21 / 37(56.8 \%)$

$6 / 21(28.6 \%)$

$13 / 37(35.1 \%)$

\begin{tabular}{|c|c|}
\hline pACS $(n=34)$ & $\boldsymbol{P}^{\S, *, \#}$ \\
\hline $68(57-73)$ & 0.161 \\
\hline $13 / 21$ & 0.449 \\
\hline $26.7(22.6-29.3)$ & 0.275 \\
\hline $15 / 34(44.1 \%)$ & 0.761 \\
\hline $10 / 34(29.4 \%)$ & 0.301 \\
\hline $27.4(23.4-31.5)$ & 0.004 \\
\hline $94(85-110)$ & 0.475 \\
\hline $5.5(5.2-5.7)$ & 0.294 \\
\hline $8.7(7.3-10)$ & 0.850 \\
\hline $2(1.5-2.5)$ & 0.917 \\
\hline $212(201-220)$ & 0.114 \\
\hline $130(116-141)$ & 0.089 \\
\hline $63(54-72)$ & 0.510 \\
\hline $90(73-122)$ & 0.550 \\
\hline $0.7(0.7-0.8)$ & 0.217 \\
\hline $142(140-143)$ & 0.765 \\
\hline $4.3(4.2-4.5)$ & 0.146 \\
\hline \multirow[t]{2}{*}{$22 / 34(64.7 \%)$} & 0.824 \\
\hline & 0.463 \\
\hline \\
\hline \multicolumn{2}{|l|}{$9 / 22(40.9 \%)$} \\
\hline & 0.488 \\
\hline \multicolumn{2}{|l|}{$11 / 22(50 \%)$} \\
\hline \multicolumn{2}{|l|}{$6 / 22(27.3 \%)$} \\
\hline \multicolumn{2}{|l|}{$5 / 22(22.7 \%)$} \\
\hline $7 / 34(20.6 \%)$ & 0.077 \\
\hline $7 / 7(100 \%)$ & 0.222 \\
\hline $24 / 34(70.6 \%)$ & 0.227 \\
\hline $8 / 24(33.3 \%)$ & 0.371 \\
\hline $11 / 34(32.4 \%)$ & 0.804 \\
\hline
\end{tabular}

Categorical variables are expressed as frequency and percentages. Continuous variables are expressed as ${ }^{5}$ mean $(95 \% \mathrm{Cl})$ or * ${ }^{*}$ edian $(25$ th- 75 th percentile).

${ }^{\S}$ Unpaired sample $T$-test or *Mann-Whitney test and ${ }^{\#} \chi^{2}$ or Fisher's exact test, as appropriate.

not meet the inclusion criteria for the current analysis. The remaining 71 patients with AI fulfilling the inclusion criteria were enrolled (Fig. 1). Of these, 37 had $1 \mathrm{mg}$-DST serum cortisol levels greater than $50 \mathrm{nmol} / \mathrm{L}$ and underwent confirmatory $2 \mathrm{mg}$-DST, giving rise to a diagnosis of pACS in 34 . The remaining three cases ( $1 \mathrm{mg}$-DST serum cortisol levels respectively $180,92.8,69.1 \mathrm{nmol} / \mathrm{L}$ ) were found to be false positives, with complete suppression on $2 \mathrm{mg}$-DST (respectively $27.6,46.9,33.5 \mathrm{nmol} / \mathrm{L}$ ). Of the four patients with $1 \mathrm{mg}$-DST above $138 \mathrm{nmol} / \mathrm{L}$ (respectively 181, 180 , $161,147 \mathrm{nmol} / \mathrm{L})$, none had a $2 \mathrm{mg}$-DST higher than $138 \mathrm{nmol} / \mathrm{L}$ (respectively $135,27.6,131,134 \mathrm{nmol} / \mathrm{L}$ ). In all, therefore, 37 patients had a post-DST cortisol level below $50 \mathrm{nmol} / \mathrm{L}$ and were defined as NFA (Fig. 1).

Table 1 describes the clinical and biochemical characteristics of all patients with AI, divided into pACS and NFA. The two groups were similar for sex, BMI and age distribution. There was no statistically significant difference in blood glucose, insulin, insulin resistance, glycated hemoglobin, sodium, potassium, creatinine, total cholesterol, HDL-cholesterol or triglycerides between the groups. Cardiovascular risk factors and comorbidities (arterial hypertension, dyslipidemia, smoking) were equally distributed among NFA and pACS, as were duration of hypertension and the number of antihypertensive, antidiabetic and hypolipidemic drugs (Table 1). The relative prevalence of T2DM was apparently higher in the pACS compared to NFA, although this was not statistically significant due to the small number of patients in each group.

The diameter of the lesions was higher in pACS than NFA patients (27.4 (95\% CI: 23-32) vs $20.2 \mathrm{~mm}$ (95\% CI: 17-23); $P=0.004)$ and positively correlated with postDST cortisol levels (rho $=0.441 ; P<0.001$ ). Hormone parameters are shown in Table 2. pACS had lower ACTH (18 (95\% CI: 15-20) vs 25 (95\% CI: 19-31) pg/mL; $P=0.028)$ and DHEAS (37.4 (18-54) vs $78(45-189) \mu \mathrm{g} / \mathrm{dL}$; $P=0.012)$ levels compared to NFA patients. No correlation was found between age and post-DST cortisol levels (rho $=0.123 ; P=0.32$ ). 
Table 2 Hormonal parameters.

\begin{tabular}{|c|c|}
\hline & Adrenal incidentalomas $(n=71$ \\
\hline Baseline cortisol $(\mathrm{nmol} / \mathrm{L})^{\S}$ & $493(434-537)$ \\
\hline ACTH $(\mathrm{pg} / \mathrm{mL})^{\S}$ & $22(18-25)$ \\
\hline Aldosterone/renin ratio* & $30(20-39)$ \\
\hline $170 \mathrm{OH}$ progesterone $(\mathrm{ng} / \mathrm{mL})^{*}$ & $0.5(0.3-0.9)$ \\
\hline DHEAS $(\mu \mathrm{g} / \mathrm{dL})^{*}$ & $48(24-88)$ \\
\hline Urinary free cortisol $(\mathrm{nmol} / 24 \mathrm{~h})^{*}$ & $121(97-184)$ \\
\hline Androstenedione $(\mathrm{ng} / \mathrm{dL})^{*}$ & $97(84-172)$ \\
\hline Urine metanephrine $(\mu \mathrm{g} / 24 \mathrm{~h})^{*}$ & $58(41-87)$ \\
\hline 1 mg-DST cortisol (nmol/L) ${ }^{*}$ & $58(42-77)$ \\
\hline Post-DST cortisol (nmoL/L) ${ }^{*}$ & $54(42-77)$ \\
\hline
\end{tabular}

\begin{tabular}{c}
\hline NFA $(n=37)$ \\
\hline $470(372-512)$ \\
$25(19-31)$ \\
$29(21-37)$ \\
$0.6(0.3-0.9)$ \\
$77.8(45-189)$ \\
$110(81-167)$ \\
$109(87-173)$ \\
$57(40-96)$ \\
$41.4(34.2-49.0)$ \\
$41.4(34.2-48.6)$ \\
\hline
\end{tabular}

\begin{tabular}{c}
\hline pACS $(n=34)$ \\
\hline $517(445-600)$ \\
$18(15-20)$ \\
$31(19-64)$ \\
$0.6(0.4-0.8)$ \\
$37.5(18-54)$ \\
$145(106-202)$ \\
$89(63-178)$ \\
$75(41-87)$ \\
$76.3(62-93)$ \\
$73.4(57-90)$ \\
\hline
\end{tabular}

\begin{tabular}{c}
\hline $\boldsymbol{P}^{\boldsymbol{S}_{\text {* * }}}$ \\
\hline 0.244 \\
0.028 \\
0.084 \\
0.773 \\
0.012 \\
0.708 \\
0.613 \\
0.685 \\
0.001 \\
0.001 \\
\hline
\end{tabular}

Continuous variable are expressed as ${ }^{\S}$ mean $(95 \% \mathrm{Cl})$ or *median (25th-75th percentile).

§Unpaired sample $T$-test or *Mann-Whitney test as appropriate.

\section{Echocardiographic findings}

Morphological analysis showed that both $\mathrm{LVMI}^{\mathrm{BSA}}$ and LVMI $^{\text {h2.7 }}$ were significantly higher in the pACS than NFA group (LVMI ${ }^{\mathrm{BSA}}$ : $90.25(71.7-110.3)$ vs $76.6(64-85) \mathrm{g} / \mathrm{m}^{2}$; $P=0.006 ;$ LVMI $^{\text {h2.7 }}: 46.3(33.6-54.6)$ vs $34.7(30-41) \mathrm{g} / \mathrm{m}^{2.7}$; $P=0.003)$. Two linear models were developed adjusting for known contributors of $\mathrm{LVMI}^{\mathrm{BSA}}$. The first model included age and BMI and the second age, BMI, HbA1c, LDL cholesterol and SBP (Table 3). Estimated marginal means of the main CV outcomes are given in Table 3 . After adjusting for all covariates a statistically significant difference in $\mathrm{LVMI}^{\mathrm{BSA}}$ and $\mathrm{LVMI}^{\mathrm{h} 2.7}$ was still found between the two groups $(P=0.001)$. There was also a significantly higher prevalence of LV hypertrophy in the pACS than the NFA group (53\% vs $13.5 \% ; P=0.001$ ), including both concentric LV hypertrophy (26.5\% vs $5.4 \%)(P=0.014)$ and eccentric LV hypertrophy ( $26.5 \%$ vs $8.1 \%)(P=0.039)$. $\mathrm{LVMI}^{\mathrm{BSA}}$ and $\mathrm{LVMI}^{\mathrm{h} 2.7}$ were both positively correlated to post-DST cortisol (rho $=0.347, P=0.004$ and $\mathrm{rho}=0.336$, $P=0.005$, respectively Fig. 2 ).

Aregression model wasused toestimate the contributors to $\mathrm{LVMI}^{\mathrm{BSA}}$ in patients with adrenal incidentalomas. The model included age, BMI, SBP, Hba1C, LDL cholesterol and post-DST cortisol. Step-wise post-DST cortisol, SBP and Hba1C were the only independent determinants of $\mathrm{LVMI}^{\mathrm{BSA}}$ explaining up to $31.7 \%$ of $\mathrm{LVMI}^{\mathrm{BSA}}$. Specifically, the post-DST cortisol level was the main independent contributor to $\mathrm{LVMI}^{\mathrm{BSA}}(P=0.002)$, accounting for $13.7 \%$ of LVMI ${ }^{\mathrm{BSA}}$ variability, followed by SBP $(9.9 \%)$ and Hba1C (8.1\%). No collinearity between SBP and post-DST cortisol was found $(\mathrm{VIF}=1)$, suggesting an independent effect of cortisol on cardiac function.

Interventricular septal thickness (IST) was greater in the pACS than in the NFA group (10.8 (95\% CI: 9.9-11.8) vs 9.9 (95\% CI: 9.3-10.3); $P=0.015)$. LVEF was similar between the two groups (63.2 (95\% CI: 61.2-65.9) vs 62.8 (95\% CI: 59.9-64.5); $P=0.786$ ). Mean TAPSE values were significantly lower in the pACS than in the NFA group (19.9 (95\% CI: 18.5-21.3) vs 22.1 (95\% CI: 20.9-23.4); $P=0.046)$.

Functional analysis showed a higher prevalence of LVDD in patients with pACS (82.3\% vs $35.1 \% ; P=0.001)$. pACS patients, compared with NFA group, had lower septal E' (7.3 (95\% CI: 6.5-8.0) vs 8.61 (95\% CI: 7.7-9.5) $\mathrm{cm} / \mathrm{s} ; P=0.027$ ), lower E'm (8.24 (95\% CI: 7.6-8.9) vs 9.57 (95\% CI: 8.6-10.5); $P=0.024)$ and higher $\mathrm{E} / \mathrm{e}^{\prime} \mathrm{m}(8.99$ (95\% CI: $8-10)$ vs 7.38 (95\% CI: $6.6-8.1) \mathrm{cm} / \mathrm{s} ; P=0.010)$. The severity of diastolic dysfunction in pACS patients appeared worse than that in the NFA group (Grade I: $38.2 \%$ vs $27 \%$; Grade II: $35.3 \%$ vs $8.1 \%$; Grade III: $8.8 \%$ vs $0 \%$ ).

To exclude that an odd distribution of T2DM prevalence among the two groups might explain some of the observed differences in the $\mathrm{CV}$ assessment, a sensitivity analysis was performed excluding both patients with T2DM and those with discrepant findings on 1-mg DST vs 2-mg DST. This produced similar findings for $\mathrm{LVMI}^{\mathrm{BSA}}$ and diastolic dysfunction (Table 4), confirming the validity of the dataset. To rule out an influence of glycemic control, $\mathrm{HbA}_{1 \mathrm{c}}$ was also included in the regression models.

\section{Arterial stiffness}

RWTT was significantly lower (123.5 (113-129) vs 129.5 (121-135) $\mathrm{m} / \mathrm{s} ; P=0.048)$, whereas PWV was significantly higher (11.05 (95\% CI: 10.4-11.7) vs 10.3 (95\% CI: 9.910.6) $\mathrm{m} / \mathrm{s} ; P=0.033)$, in the pACS compared to the NFA group. After adjusting for age and BMI, a significant difference in PWV was found between the two groups $(P=0.040$, Table 3$)$. 
Table 3 Cardiac and arterial stiffness features comparisons between groups.

\begin{tabular}{|c|c|c|c|}
\hline & NFA $(n=37)$ & pACS $(n=34)$ & $P$ value \\
\hline \multicolumn{4}{|l|}{ ANCOVA model ${ }^{a}$} \\
\hline \multicolumn{4}{|l|}{ Echocardiographic measurements } \\
\hline LV end-diastolic diameter (mm) & $45.6(43.9-47.2)$ & $47.1(45.5-48.8)$ & 0.194 \\
\hline IST $(\mathrm{mm})$ & $10.0(9.5-10.5)$ & $10.7(10.2-11.3)$ & 0.042 \\
\hline Posterior wall thickness (mm) & $8.4(7.9-8.9)$ & $9.1(8.6-9.6)$ & 0.071 \\
\hline Relative wall thickness & $0.41(0.39-0.43)$ & $0.42(0.4-0.45)$ & 0.279 \\
\hline LV mass $(g)$ & $141(127-166)$ & $168(153-182)$ & 0.014 \\
\hline LV mass ${ }^{\mathrm{BSA}}\left(\mathrm{g} / \mathrm{m}^{2}\right)$ & $77.0(70-85)$ & $92.8(85.5-100.2)$ & 0.009 \\
\hline $\operatorname{LV}_{\text {mass }}{ }^{\mathrm{h} 2.7}\left(\mathrm{~g} / \mathrm{m}^{2.7}\right)$ & $37.3(33.5-40.9)$ & $44.9(41.3-48.7)$ & 0.004 \\
\hline Left atrial size $(\mathrm{mm})$ & $36.2(34.6-37.8)$ & $36.3(34.6-37.9)$ & 0.955 \\
\hline LV ejection fraction (\%) & $63.1(60.9-65.3)$ & $60.7(60.7-65.0)$ & 0.850 \\
\hline $\mathrm{E} / \mathrm{A}$ & $0.9(0.8-1.1)$ & $1.0(0.8-1.2)$ & 0.530 \\
\hline $\mathrm{E}^{\prime} \mathrm{l}(\mathrm{cm} / \mathrm{s})$ & $10.3(9.3-11.3)$ & $9.5(8.5-10.3)$ & 0.211 \\
\hline$E^{\prime} \mathrm{s}(\mathrm{cm} / \mathrm{s})$ & $8.5(7.7-9.2)$ & $7.5(6.7-8.2)$ & 0.093 \\
\hline$E^{\prime} m(\mathrm{~cm} / \mathrm{s})$ & $9.4(8.6-10.2)$ & $8.4(7.7-9.2)$ & 0.065 \\
\hline$E / e^{\prime} \mid$ & $7.0(6.2-7.9)$ & $7.9(7.1-8.8)$ & 0.155 \\
\hline E/e's & $8.6(7.5-9.6)$ & $10.2(9.1-11.3)$ & 0.044 \\
\hline$E / e^{\prime} m$ & $7.6(6.8-8.3)$ & $8.7(7.9-9.6)$ & 0.061 \\
\hline TAPSE $(\mathrm{mm})$ & $21.9(20.8-23.1)$ & $20.3(18.9-21.5)$ & 0.064 \\
\hline \multicolumn{4}{|l|}{ Arterial stiffness measurements } \\
\hline Systolic blood pressure (mmHg) & $137.2(131.1-143.4)$ & $136.8(131.1-142.9)$ & 0.917 \\
\hline Diastolic blood pressure $(\mathrm{mmHg})$ & $83.3(79.3-87.2)$ & $83.1(79.2-86.9)$ & 0.946 \\
\hline Mean blood pressure $(\mathrm{mmHg})$ & $110.3(106-115)$ & $109.9(106-114)$ & 0.918 \\
\hline Heart rate (bpm) & $69.9(65.1-74.7)$ & $76.6(71.1-82.1)$ & 0.143 \\
\hline Reflected wave transit time $(\mathrm{m} / \mathrm{s})$ & $127.5(123-132)$ & $120.6(115.9-125.3)$ & 0.031 \\
\hline Pulse-wave velocity $(\mathrm{m} / \mathrm{s})$ & $10.3(9.9-10.8)$ & $11.0(10.5-11.5)$ & 0.040 \\
\hline \multicolumn{4}{|l|}{ ANCOVA model ${ }^{b}$} \\
\hline \multicolumn{4}{|l|}{ Echocardiographic measurements } \\
\hline LV end-diastolic diameter (mm) & $45.6(44.0-47.3)$ & $47.3(45.5-49.0)$ & 0.198 \\
\hline IST $(\mathrm{mm})$ & $9.9(9.4-10.4)$ & $10.7(10.2-11.2)$ & 0.015 \\
\hline Posterior wall thickness (mm) & $8.4(7.9-9)$ & $9.1(8.5-9.6)$ & 0.047 \\
\hline Relative wall thickness & $0.40(0.39-0.4)$ & $0.42(0.39-0.43)$ & 0.193 \\
\hline LV mass $(g)$ & $140(126-155)$ & 169 (154-184) & 0.013 \\
\hline $\mathrm{LV} \operatorname{mass}^{\mathrm{BSA}}\left(\mathrm{g} / \mathrm{m}^{2}\right)$ & $76.6(69.6-83.6)$ & $95.3(88.0-102.5)$ & 0.001 \\
\hline $\operatorname{LV}_{\text {mass }}{ }^{\mathrm{h} 2.7}\left(\mathrm{~g} / \mathrm{m}^{2.7}\right)$ & $36.2(32.8-39.6)$ & $46.1(42.5-49.6)$ & 0.001 \\
\hline Left atrial size $(\mathrm{mm})$ & $35.5(34.1-36.9)$ & $35.9(34.3-37.5)$ & 0.685 \\
\hline LV ejection fraction (\%) & $63.4(61.09-65.7)$ & $62.7(60.4-65.1)$ & 0.692 \\
\hline E/A & $0.9(0.79-1.0)$ & $0.9(0.8-1.1)$ & 0.524 \\
\hline $\mathrm{E}^{\prime} \mid(\mathrm{cm} / \mathrm{s})$ & $10.4(9.3-11.5)$ & $9.3(8.1-10.5)$ & 0.199 \\
\hline $\mathrm{E}^{\prime} \mathrm{s}(\mathrm{cm} / \mathrm{s})$ & $8.5(7.7-9.3)$ & $7.4(6.4-8.2)$ & 0.059 \\
\hline $\mathrm{E}^{\prime} \mathrm{m}(\mathrm{cm} / \mathrm{s})$ & $9.4(8.6-10.2)$ & $8.3(7.4-9.2)$ & 0.067 \\
\hline$E / e^{\prime} \mid$ & $6.8(5.9-7.8)$ & $8.0(6.9-9.1)$ & 0.125 \\
\hline E/e's & $8.3(7.2-9.5)$ & $10.3(9.0-11.6)$ & 0.028 \\
\hline $\mathrm{E} / \mathrm{e}^{\prime} \mathrm{m}$ & $7.4(6.6-8.3)$ & $8.85(7.8-9.8)$ & 0.044 \\
\hline TAPSE $(\mathrm{mm})$ & $22.2(21.1-23.3)$ & $20.2(18.9-21.6)$ & 0.036 \\
\hline
\end{tabular}

${ }^{a, b}$ ANCOVA models for group comparisons with possible autonomous cortisol secretion (pACS) as fixed factor and the following as covariates: modela, age and BMI; model ${ }^{b}$, age, BMI, SBP, LDL cholesterol and $\mathrm{Hba} 1 \mathrm{C}$. Values represent the estimated marginal means (lower-upper limit of $95 \% \mathrm{Cl}$ ).

\section{Discussion}

Our findings suggest that exposure to mild levels of autonomous cortisol secretion sustains structural and functional changes of the LV and medium-sized vessel arterial wall that may account for the observed increase in $\mathrm{CV}$ events and related mortality described in other studies.
In our cohort of patients with AI, both mean LVMI and prevalence of LV hypertrophy was higher in pACS than in NFA patients. LVMI is a sensitive indicator of cardiac end-organ damage and an independent risk factor for the development of heart failure. LV hypertrophy is the hallmark of several detrimental cardiovascular diseases and is associated with a worse prognosis after cardiac events (18). We also find a mild positive 
A

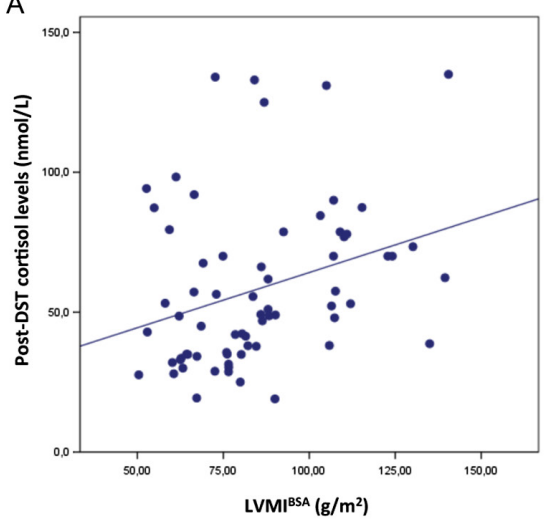

B

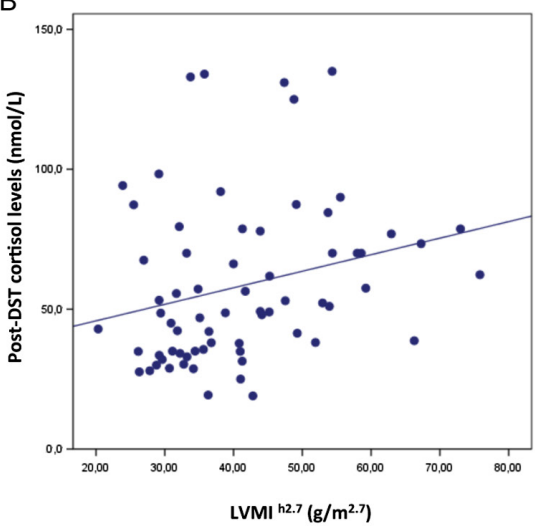

\section{Figure 2}

Correlation between post-DST cortisol levels and left ventricular mass index normalized to BSA (LVMI $\left.{ }^{\mathrm{BSA}}\right)(\mathrm{A})$ and normalized to height ${ }^{2.7}$ (LVMI $^{\text {h2.7) }}$ (B). correlation between both $\mathrm{LVMI}^{\mathrm{BSA}}$ and $\mathrm{LVMI}^{\mathrm{h} 2.7}$ and post-DST cortisol. For the first time, we documented a diastolic dysfunction associated with pACS. The presence of LVDD is considered an independent risk factor for heart failure and death from cardiac causes. LVDD is also associated with a reduced quality of life $(19,20)$. TAPSE has been proposed as a simple and reproducible parameter for qualitative RV systolic function. We found a mild reduction of TAPSE in pACS compared to NFA patients. Although TAPSE may slightly overestimate or underestimate RV function because of cardiac translation, it still correlates well with the parameters estimating RV global systolic function (14).

Arterial stiffness analysis showed that patients with pACS had significantly higher PWV and lower RWTT. PWV is the most validated method for the noninvasive quantification of arterial stiffness and is considered the gold standard index (21). Increased PWV, and thus arterial stiffness, has been associated with increased morbidity and cardiovascular mortality and is considered an independent early predictor of coronary heart disease and stroke in the general population (22). In our study, compared to NFA patients, pACS patients presented a worse metabolic profile, although this difference was not statistically significant. There was no significant difference between the two groups in age, gender distribution, BMI, arterial hypertension, T2DM, dyslipidemia and smoking habit, all important parameters associated with increased cardiovascular risk; therefore, these were reasonably excluded as possible confounders. The two groups also showed similar duration of arterial hypertension and number of antihypertensive drugs.

Cortisol is thought to have direct relevant effects on cardiac function: it potentiates cardiac angiotensin II and noradrenaline responsiveness and also stimulates the local renin-angiotensin system (4). Complex mechanisms including endothelial damage, activation of inflammation, increased oxidative stress and fibroproliferation are correlated with high cortisol levels, leading to functional and structural change in the heart and blood vessels. An increased prevalence of LV hypertrophy and LV diastolic dysfunction (albeit with preserved LV ejection fraction)

Table 4 Sensitivity analysis of cardiac and arterial stiffness excluding patients with of diabetes mellitus or discrepancies between the $1 \mathrm{mg}$ DST and 2-mg DST.

\begin{tabular}{l}
\hline \\
\hline Pulse-wave velocity $(\mathrm{m} / \mathrm{s})^{\S}$ \\
LV mass \\
LV mass $\left(\mathrm{g} / \mathrm{m}^{2}\right)^{\text {h2.7 }}\left(\mathrm{g} / \mathrm{m}^{2.7}\right)^{*}$ \\
LV hypertrophy \\
E's $(\mathrm{cm} / \mathrm{s})^{\S}$ \\
$E^{\prime} \mathrm{m}(\mathrm{cm} / \mathrm{s})^{\S}$ \\
E/e'l \\
E/e's ${ }^{\S}$ \\
E/e' $\mathrm{m}^{\S}$ \\
Diastolic dysfunction ${ }^{+}$
\end{tabular}

\begin{tabular}{c}
\hline Adrenal incidentalomas $(n=59)$ \\
\hline $10.6(10.2-11)$ \\
$76.1(64.3-86)$ \\
$34.1(30.7-41)$ \\
$19 / 59(32.2 \%)$ \\
$8.0(7.3-8.7)$ \\
$9.1(8.4-9.8)$ \\
$7.0(6.3-7.7)$ \\
$9.0(8.1-9.9)$ \\
$7.7(7.1-8.4)$ \\
$33 / 59(55.9 \%)$
\end{tabular}

\begin{tabular}{c}
\hline NFA $(n=32)$ \\
\hline $10.3(9.9-10.7)$ \\
$75.9(63.4-80.1)$ \\
$33.2(30.1-36.6)$ \\
$5 / 32(15.6 \%)$ \\
$8.6(7.6-9.5)$ \\
$9.7(8.7-10.8)$ \\
$6.3(5.6-7.1)$ \\
$8.0(5.6-7.1)$ \\
$7.0(6.2-7.7)$ \\
$10 / 32(31.25 \%)$
\end{tabular}

\begin{tabular}{crrr}
\hline PACS $(n=27)$ & & $\boldsymbol{P}^{\S, *,+}$ \\
\hline $11.0(10.3-11.7)$ & & 0.039 \\
$83.8(64.7-105.5)$ & & 0.032 \\
$37.4(31.1-48.8)$ & & 0.022 \\
$14 / 27(51.8 \%)$ & & 0.003 \\
$7.3(6.4-8.2)$ & & 0.039 \\
$8.3(7.6-9.1)$ & & 0.022 \\
$7.8(6.7-8.9)$ & & 0.029 \\
$10.2(8.6-11.7)$ & & 0.021 \\
$8.6(7.6-9.6)$ & & 0.011 \\
$23 / 27(85.2 \%)$ & 0.001 \\
\hline
\end{tabular}

Continuous variable are expressed as ${ }^{\S}$ mean (lower-upper limit of $95 \% \mathrm{Cl}$ ) or *median (25th-75th percentile). Categorical variables are expressed as frequency and percentages.

§Unpaired sample $T$-test or *Mann-Whitney test and ${ }^{+} \mathrm{X}$-square as appropriate. 
are consistently found in Cushing's syndrome (CS). In patients with CS, systolic and diastolic dysfunction can develop independently of the presence of hypertension $(17,23,24,25)$. We found a higher prevalence of LV hypertrophy in pACS than that reported in overt CS by previous echocardiography-based studies, where LV hypertrophy was found in $24-42 \%$ of affected patients $(23,25,26,27)$. However, cardiac hypertrophy increases with age, and in those studies on $\operatorname{CS}(23,25,26,27)$ the mean age was significantly lower than in our cohort of pACS patients (39-41 vs 65 years). Finally, a recent report on arterial stiffness in CS reported structural changes in the arterial wall occurring independently of blood pressure levels (28).

Recent studies suggest that even patients lacking the full clinical picture of CS having an adrenal incidentaloma and a non-suppressed cortisol after DST suffer from increased cardiovascular events and mortality when compared to NFA $(5,7,29,30)$. To our knowledge, this is the first study evaluating the relationship between pACS, LV function and structure and arterial stiffness and the first to describe a dose-response relationship between post-DST cortisol and LVMI. Only two previous studies presented data about echocardiographic findings of subclinical hypercortisolism. However, both were completed before the publication of the 2016 ESE Guidelines defining pACS (2). In 2013, Iacobellis and coworkers reported echocardiographic data on 6 patients with mild CS compared with 40 patients with NFA. In this study, mild CS was defined by two positive tests among UFC $>70 \mu \mathrm{g}$ per $24 \mathrm{~h}$, post-DST serum cortisol levels $>138 \mathrm{nmol} / \mathrm{L}(5 \mu \mathrm{g} / \mathrm{dL})$ or ACTH levels $<10 \mathrm{pg} / \mathrm{mL}$. Patients matching these criteria had a higher LVM than those without (8). In 2015, Evran and coworkwers described the US findings of 5 patients with 'subclinical Cushing's syndrome' defined as a post-DST cortisol values $>50 \mathrm{nmol} / \mathrm{L}(1.8 \mu \mathrm{g} / \mathrm{dL})$ and $\mathrm{ACTH}<10 \mathrm{pg} / \mathrm{mL}$. No echocardiographic differences were found between the 5 patients with 'subclinical Cushing's syndrome' and a group of 76 patients without CS (9).

The strengths of the present study are the presence of a confirmatory test for the diagnosis of pACS, the balanced distribution between the two groups and its prospective design: all echocardiography and arterial stiffness measurements were performed by the same clinician blinded to the diagnosis of pACS or NFA (blinded outcome assessor).

However, the study also has a number of limitations. The size of the two groups, although significantly higher than in other published studies, is still low to provide definitive data. In addition, there was no control group (patients without adrenal adenoma). Moreover, 2D-echocardiogram and BPlab are not the gold standard methods to assess cardiac hypertrophy and arterial stiffness. Cardiac MRI or aortic catheterization would have provided more definitive findings. However, they are more affordable, have good reproducibility and are often used in the clinical setting for population studies $(14,31$, 32), expanding the applicability of our findings. Finally, some recent reports suggested that patients with NFA may also carry an increased CV risk compared with the general population, thus our study may underestimate the magnitude of cardiac damage associated with pACS. Among the hypotheses proposed, there is the possibility that NFAs produce excess cortisol in a cyclic manner, or during stress, or release excess steroid precursors, such as deoxycorticosterone and corticosterone $(6,33,34)$.

In conclusion, our study shows that possible autonomous cortisol secretion (pACS) can sustain early cardiac and vascular dysfunction even in asymptomatic patients. Our results suggest that the finding of post-DST cortisol levels above $50 \mathrm{nmol} / \mathrm{L}$ requires careful monitoring of cardiovascular risk and long-term evaluation in nonoperated patients. These results underline the need for further studies, including second line cardiovascular assessment, to correctly characterize the molecular mechanism or pathway through which mild autonomous secretion can induce cardiac damage.

Declaration of interest

The authors declare that there is no conflict of interest that could be perceived as prejudicing the impartiality of this study.

\section{Funding}

This study was supported in part by the Italian Ministry of University and Research (MIUR) grant SIR No. RBSI141LY2.

\section{Author contribution statement}

E S and M M researched the data, wrote the manuscript, contributed to the discussion and edited the manuscript; D D performed cardiac ultrasound and measurement of arterial stiffness; $L R, M D G$ and $R$ P enrolled and evaluated patients and controls; F V critically revised cardiovascular data; E G and M A V collected and analyzed data; A V provided statistical support; S M, A L and A M I established the study protocol, coordinated the study and critically revised the manuscript.

\section{Acknowledgements}

The authors would like to thank Dr Marie-Hélène Hayles for revision of the English text. 


\section{References}

1 Debono M \& Newell-Price J. Subclinical hypercortisolism in adrenal incidentaloma. Current Opinion in Endocrinology, Diabetes and Obesity 201522 185-192. (https://doi.org/10.1097/ MED.0000000000000151)

2 Fassnacht M, Arlt W, Bancos I, Dralle H, Newell-Price J, Sahdev A, Tabarin A, Terzolo M, Tsagarakis S \& Dekkers OM. Management of adrenal incidentalomas: European Society of Endocrinology Clinical Practice Guideline in collaboration with the European Network for the Study of Adrenal Tumors. European Journal of Endocrinology 2016 175 G1-G34. (https://doi.org/10.1530/EJE-16-0467)

3 Pivonello R, Isidori AM, De Martino MC, Newell-Price J, Biller BM \& Colao A. Complications of Cushing's syndrome: state of the art. Lancet Diabetes and Endocrinology 2016 4 611-629. (https://doi. org/10.1016/S2213-8587(16)00086-3)

4 Isidori AM, Graziadio C, Paragliola RM, Cozzolino A, Ambrogio AG, Colao A, Corsello SM, Pivonello R \& Group ABCS. The hypertension of Cushing's syndrome: controversies in the pathophysiology and focus on cardiovascular complications. Journal of Hypertension 2015 33 44-60. (https://doi.org/10.1097/HJH.0000000000000415) 5 Debono M, Bradburn M, Bull M, Harrison B, Ross RJ \& NewellPrice J. Cortisol as a marker for increased mortality in patients with incidental adrenocortical adenomas. Journal of Clinical Endocrinology and Metabolism 201499 4462-4470. (https://doi.org/10.1210/ jc.2014-3007)

6 Di Dalmazi G \& Pasquali R. Adrenal adenomas, subclinical hypercortisolism, and cardiovascular outcomes. Current Opinion in Endocrinology, Diabetes and Obesity 201522 163-168. (https://doi. org/10.1097/MED.0000000000000153)

7 Morelli V, Palmieri S, Lania A, Tresoldi A, Corbetta S, Cairoli E, Eller-Vainicher C, Arosio M, Copetti M, Grossi E et al. Cardiovascular events in patients with mild autonomous cortisol secretion: analysis with artificial neural networks. European Journal of Endocrinology 2017 177 73-83. (https://doi.org/10.1530/EJE-17-0047)

8 Iacobellis G, Petramala L, Barbaro G, Kargi AY, Serra V, Zinnamosca L, Colangelo L, Marinelli C, Ciardi A, De Toma G et al. Epicardial fat thickness and left ventricular mass in subjects with adrenal incidentaloma. Endocrine 201344 532-536. (https://doi.org/10.1007/ s12020-013-9902-5)

9 Evran M, Akkus G, Berk Bozdogan I, Gok M, Deniz A, Sert M \& Tetiker T. Carotid intima-media thickness as the cardiometabolic risk indicator in patients with nonfunctional adrenal mass and metabolic syndrome screening. Medical Science Monitor 201622 991-997. (https://doi.org/10.12659/MSM.897714)

10 Mancia G, Fagard R, Narkiewicz K, Redon J, Zanchetti A, Bohm M, Christiaens T, Cifkova R, De Backer G, Dominiczak A et al. 2013 ESH/ESC Guidelines for the management of arterial hypertension: the Task Force for the management of arterial hypertension of the European Society of Hypertension (ESH) and of the European Society of Cardiology (ESC). Journal of Hypertension 201331 1281-1357. (https://doi.org/10.1097/01.hjh.0000431740.32696.cc)

11 Authors/Task Force. ESC Guidelines on diabetes, pre-diabetes, and cardiovascular diseases developed in collaboration with the EASD: the Task Force on diabetes, pre-diabetes, and cardiovascular diseases of the European Society of Cardiology (ESC) and developed in collaboration with the European Association for the Study of Diabetes (EASD). European Heart Journal 201334 3035-3087. (https:// doi.org/10.1093/eurheartj/eht108)

12 Catapano AL, Graham I, De Backer G, Wiklund O, Chapman MJ, Drexel H, Hoes AW, Jennings CS, Landmesser U, Pedersen TR et al. 2016 ESC/EAS Guidelines for the management of dyslipidaemias. European Heart Journal 201637 2999-3058. (https://doi.org/10.1093/ eurheartj/ehw272)

13 Newell-Price J, Trainer P, Besser M \& Grossman A. The diagnosis and differential diagnosis of Cushing's syndrome and pseudo-Cushing's states. Endocrine Reviews 199819 647-672. (https://doi.org/10.1210/ edrv.19.5.0346)

14 Lang RM, Badano LP, Mor-Avi V, Afilalo J, Armstrong A, Ernande L, Flachskampf FA, Foster E, Goldstein SA, Kuznetsova T et al. Recommendations for cardiac chamber quantification by echocardiography in adults: an update from the American Society of Echocardiography and the European Association of Cardiovascular Imaging. European Heart Journal: Cardiovascular Imaging 201516 233-270. (https://doi.org/10.1093/ehjci/jev014)

15 Cuspidi C, Meani S, Negri F, Giudici V, Valerio C, Sala C, Zanchetti A \& Mancia G. Indexation of left ventricular mass to body surface area and height to allometric power of 2.7: is the difference limited to obese hypertensives? Journal of Human Hypertension 200923 728-734. (https://doi.org/10.1038/jhh.2009.16)

16 Nagueh SF, Appleton CP, Gillebert TC, Marino PN, Oh JK, Smiseth OA, Waggoner AD, Flachskampf FA, Pellikka PA \& Evangelista A. Recommendations for the evaluation of left ventricular diastolic function by echocardiography. Journal of the American Society of Echocardiography 200922 107-133. (https://doi. org/10.1016/j.echo.2008.11.023)

17 Bayram NA, Ersoy R, Aydin C, Gul K, Keles T, Topaloglu O, Durmaz T, Bozkurt E \& Cakir B. Assessment of left ventricular functions by tissue Doppler echocardiography in patients with Cushing's disease. Journal of Endocrinological Investigation 200932 248-252. (https://doi. org/10.1007/BF03346461)

18 Levy D, Garrison RJ, Savage DD, Kannel WB \& Castelli WP. Prognostic implications of echocardiographically determined left ventricular mass in the Framingham Heart Study. New England Journal of Medicine 1990322 1561-1566. (https://doi.org/10.1056/ NEJM199005313222203)

19 Halley CM, Houghtaling PL, Khalil MK, Thomas JD \& Jaber WA. Mortality rate in patients with diastolic dysfunction and normal systolic function. Archives of Internal Medicine 2011171 1082-1087. (https://doi:10.1001/archinternmed.2011.244)

20 Abhayaratna WP, Marwick TH, Smith WT \& Becker NG. Characteristics of left ventricular diastolic dysfunction in the community: an echocardiographic survey. Heart 200692 1259-1264. (https://doi.org/10.1136/hrt.2005.080150)

21 Cavalcante JL, Lima JA, Redheuil A \& Al-Mallah MH. Aortic stiffness: current understanding and future directions. JACC: Journal of the American College of Cardiology 201157 1511-1522. (https://doi. org/10.1016/j.jacc.2010.12.017)

22 Mattace-Raso FU, van der Cammen TJ, Hofman A, van Popele NM, Bos ML, Schalekamp MA, Asmar R, Reneman RS, Hoeks AP, Breteler MM et al. Arterial stiffness and risk of coronary heart disease and stroke: the Rotterdam Study. Circulation 2006113 657-663. (https://doi.org/10.1161/CIRCULATIONAHA.105.555235)

23 Muiesan ML, Lupia M, Salvetti M, Grigoletto C, Sonino N, Boscaro M, Rosei EA, Mantero F \& Fallo F. Left ventricular structural and functional characteristics in Cushing's syndrome. JACC: Journal of the American College of Cardiology 200341 2275-2279. (https://doi. org/10.1016/S0735-1097(03)00493-5)

24 Fallo F, Budano S, Sonino N, Muiesan ML, Agabiti-Rosei E \& Boscaro M. Left ventricular structural characteristics in Cushing's syndrome. Journal of Human Hypertension 1994 8 509-513.

25 Pereira AM, Delgado V, Romijn JA, Smit JW, Bax JJ \& Feelders RA. Cardiac dysfunction is reversed upon successful treatment of Cushing's syndrome. European Journal of Endocrinology 2010162 331-340. (https://doi.org/10.1530/EJE-09-0621)

26 Yiu KH, Marsan NA, Delgado V, Biermasz NR, Holman ER, Smit JW, Feelders RA, Bax JJ \& Pereira AM. Increased myocardial fibrosis and left ventricular dysfunction in Cushing's syndrome. European Journal of Endocrinology 2012166 27-34. (https://doi.org/10.1530/EJE-110601)

27 Toja PM, Branzi G, Ciambellotti F, Radaelli P, De Martin M, Lonati LM, Scacchi M, Parati G, Cavagnini F \& Pecori Giraldi F. 
Clinical relevance of cardiac structure and function abnormalities in patients with Cushing's syndrome before and after cure. Clinical Endocrinology 201276 332-338. (https://doi.org/10.1111/j.13652265.2011.04206.x)

28 Battocchio M, Rebellato A, Grillo A, Dassie F, Maffei P, Bernardi S, Fabris B, Carretta R \& Fallo F. Ambulatory arterial stiffness indexes in Cushing's syndrome. Hormone and Metabolic Research 201749 214-220. (https://doi.org/10.1055/s-0043-100385)

29 Di Dalmazi G, Vicennati V, Garelli S, Casadio E, Rinaldi E, Giampalma E, Mosconi C, Golfieri R, Paccapelo A, Pagotto U et al. Cardiovascular events and mortality in patients with adrenal incidentalomas that are either non-secreting or associated with intermediate phenotype or subclinical Cushing's syndrome: a 15-year retrospective study. Lancet Diabetes and Endocrinology 20142 396-405. (https://doi.org/10.1016/S2213-8587(13)70211-0)

30 Morelli V, Reimondo G, Giordano R, Della Casa S, Policola C, Palmieri S, Salcuni AS, Dolci A, Mendola M, Arosio M et al. Longterm follow-up in adrenal incidentalomas: an Italian multicenter study. Journal of Clinical Endocrinology and Metabolism 201499 827-834. (https://doi.org/10.1210/jc.2013-3527)
31 Kotovskaya YV, Kobalava ZD \& Orlov AV. Validation of the integration of technology that measures additional 'vascular' indices into an ambulatory blood pressure monitoring system. Medical Devices 20147 91-97. (https://doi.org/10.2147/MDER.S61839)

32 Ageenkova OA \& Purygina MA. Central aortic blood pressure, augmentation index, and reflected wave transit time: reproducibility and repeatability of data obtained by oscillometry. Vascular Health and Risk Management 20117 649-656. (https://doi.org/10.2147/ VHRM.S24877)

33 Androulakis II, Kaltsas GA, Kollias GE, Markou AC, Gouli AK, Thomas DA, Alexandraki KI, Papamichael CM, Hadjidakis DJ \& Piaditis GP. Patients with apparently nonfunctioning adrenal incidentalomas may be at increased cardiovascular risk due to excessive cortisol secretion. Journal of Clinical Endocrinology and Metabolism 201499 2754-2762. (https://doi.org/10.1210/jc.20134064)

34 Akkan T, Altay M, Unsal Y, Dagdeviren M \& Beyan E. Nonfunctioning adrenal incidentaloma affecting central blood pressure and arterial stiffness parameters. Endocrine $2017 \mathbf{5 8} 513-520$. (https://doi.org/10.1007/s12020-017-1439-6)

Received 25 November 2017

Revised version received 11 February 2018

Accepted 6 March 2018 